\title{
The Efficacy of Accelerated Test Methods to Evaluate Alkali Silica Reactivity of Recycled Concrete Aggregates
}

\author{
Robert Johnson ${ }^{1}$ and Medhat H. Shehata ${ }^{2 *}$ \\ ${ }^{1}$ Quality Assurance Manager, Lafarge Canada Inc. Edmonton, Alberta, Canada \\ ${ }^{2}$ Professor, Department of Civil Engineering, Ryerson University, Toronto, Ontario, Canada
}

\begin{abstract}
The effectiveness of accelerated tests in evaluating the Alkali-Silica Reactivity of Recycled Concrete Aggregates was evaluated. The Accelerated Mortar Bar Test was found effective for evaluating potential alkali-reactivity when the test variables, such as crushing method and absorption, are carried out in a well-defined process. The method of crushing was found to have significant impact on the expansion. The Concrete Microbar Test (CMBT) provides good correlation to the expansion of Concrete Prisms incorporating Supplementary Cementing Materials when an expansion limit of $0.10 \%$ at 56 days or $0.04 \%$ at 28 days were used, based on the limited number of tests carried out here.
\end{abstract}

Key Words: Recycled Concrete Aggregate, Alkali-Silica Reaction, Accelerated mortar bar test; Expansion; Concrete Microbar Test; Preventive measures; Sample preparation

\section{Introduction}

Alkali Silica Reaction (ASR) is a chemical reaction between the alkali hydroxide in concrete pore solution and reactive silica found in some aggregates, which react to form an amorphous 
gel. As this gel absorbs water and expands, internal tensile forces develop which eventually result in cracking. Over time, this cracking increases and will often result in the structure deteriorating beyond acceptable service requirements [1]. Less intensive ASR attacks are still dangerous since they provide ingress points for other deleterious substances to enter the concrete. This leads to severe reduction in resistance to chlorides, freeze-thaw, sulphate and carbonation [2].

The Concrete Prism Test (CPT) is widely recognized as the most reliable laboratory test to evaluate reactivity of aggregates and efficacy of preventive measures [3]. The results at 1 year are reported in comparison to an expansion limit of $0.040 \%$ which has been specified as the limit of expansion with a low likelihood of deleterious effects in field conditions [4]. However, if the test is being conducted to study the efficacy of preventive measures including Supplementary Cementing Materials (SCM), the expansion limit of $0.040 \%$ applies at 2 years.

A shortfall of the CPT is alkali leaching which takes place during the test period. The leaching process, which involves washing away alkalis from the samples, reduces the alkali concentrations in the prisms over time until the ASR reaction stops. This limits the effective test duration and reliability $[5,6,7]$. Another limitation is the sensitivity to the storage conditions during testing; it was found that the expansion of specimens was lower when cured with a larger number of specimens in a single container [8]. However, the CPT still provides the best correlation to field blocks or structures with reactive aggregates [9]. 
In many cases, the test duration of the CPT is too long; for this reason, the Accelerated Mortar Bar Test (AMBT) was developed. Studies have shown the results of this test to have a good correlation with those from the CPT $[10,11]$; however, other studies showed a lack of correlation between the two tests [12]. The obvious advantage of the AMBT is its short duration which made it widely used as a screening test for evaluating reactivity of aggregates. Aggregates that failed the AMBT are recommended to be evaluated by the CPT to confirm the results [3].

The Concrete Microbar Test (CMBT) was developed from the Chinese accelerated mortar bar test, which used a fine aggregate size similar to the AMBT but using a larger specimen. However, it was found that larger aggregate sizes were more sensitive to ASR expansion [12]. This work led to the development of the CMBT using coarse aggregate sizes as defined in RILEM AAR 5 [13] which is used mainly to evaluate alkali-carbonate reactivity. To minimize the required aggregate, processing the largest possible aggregate size is required; however, this led to a decrease in sensitivity to expansion [3,14]. The research of Grattan-Bellew et. al. [15,16] offered several different expansion limits, from $0.09 \%$ at 30 days for siliceous limestone to 0.040\% for other reactive aggregates. Andic-Cakir et. al. 2009 [14] suggested that the CMBT underestimates the expansion of an aggregate compared to the AMBT.

ASR can be severe enough to cause a concrete structure, or parts of it, to be demolished. The demolished structure would need to be disposed of in landfill unless the material can be diverted. The waste from the original structure can be used as Recycled Concrete Aggregate (RCA) to build new structures. In this case, the new structure may simply inherit the same ASR condition from latent reactive silica remaining in the original material. Moreover, stockpiles of RCA could 
contain materials from different sources and, in many situations, it may not be easy to know if the stockpile contained RCA produced from ASR-affected concrete. Petrographic examination offers the ability to examine RCA particles for evidence of ASR such as the presence of gel; however, the feasibility and cost effectiveness of this approach are subject to the feasibility of obtaining representative samples of the stockpile. Research showed that the expansion of RCA made from ASR-affected concrete exhibits equal and often greater expansion than that of the original concrete. Li \& Gress [17] and Shehata et. al. [18] reported that RCA derived from ASRaffected concrete exhibited similar expansion to virgin aggregate. Scott \& Gress [19] and Grattan-Bellew [20] reported results where the expansion of RCA derived from ASR affected concrete was greater than the virgin aggregate. Li \& Gress [17] suggested that the concerns of utilizing RCA produced from ASR-affected concrete are: (1) the reactivation of ASR due to the increased alkali content of modern cements; (2) the expansion of existing ASR products that were desiccated during the processing of the RCA, and (3) exposure of unused reactive silica in coarse aggregate during crushing.

Using scanning electron microscopy, Shehata et al. [18] showed that processing old concrete to produce RCA produces microcracks within the virgin reactive aggregates which provided access for alkalis to fresh silica within the particles. In addition, the level of preventive measures required was higher in the case of concrete containing reactive RCA compared to that in concrete with the same virgin reactive aggregates used in the RCA [18].

As is the case with virgin aggregate, an accelerated test to evaluate reactivity of RCA and efficacy of preventive measures is needed. In an earlier study [18], a good correlation was found 
between the 14-day expansion of the AMBT modified to take the absorption of RCA into consideration and the one or 2-year expansions of the CPT. The one year expansion for the CPT was used in case of samples without preventive measures and the 2 years expansion for samples with preventive measures. However, the study covers only one source of RCA which was produced from a test block containing a siliceous limestone reactive aggregate from Ottawa, Ontario (Spratt). At a later stage, a study by Adams et al. [21] proposed a detailed AMBT procedure for testing RCA. The main change in the procedure compared to the standard ASTM C1260 was addressing the high absorption capacity of RCA, and providing a standard procedures for washing RCA, as excessive washing can reduce the alkali content of the particles. Using the proposed procedures, six different RCA sources were tested, four of which were tested at four different laboratories to evaluate the inter-lab variability. The results showed the AMBT to be effective in predicting the reactivity of RCA from different sources [21].

The CMBT addresses some of the limitations of the CPT and the AMBT. It allows the use of coarse aggregate which addresses issues associated with processing coarse RCA in terms of obtaining material that is non-representative of the original RCA with respect to stone-to-residual paste ratio. Comparing CMBT to CPT, the main advantage of the CMBT lies in its shorter test duration. There is a lack of available research on the effectiveness of the CMBT in evaluating reactivity of RCA. Shehata et al. 2010 [18] provided limited results which showed the CMBT to produce promising results in evaluating the reactivity of RCA. However, the expansion values at 28 days were lower than what would be expected based on expansion values obtained by CPT and AMBT. 
This paper focuses on examining the effects of variability in major steps of sample preparation in the AMBT on the expansion of specimens prepared with RCA. The examined testing steps are method of crushing, possible error in the tested absorption values, and the effect of washing the processed RCA prior to use. This is done in an attempt to identify the significance of each of the steps on the obtained results, and highlight the importance of developing and following standardized procedures. In addition, the efficacy of the concrete microbars in testing ASR, and evaluating the reactivity of RCA and efficacy of preventive measures is also examined.

\section{Materials and experimental details}

\subsection{Materials}

Four of the RCA types used in this study were produced from test blocks that were part of an outdoor exposure site, administered by Canada Centre for Mineral and Energy Technology (CANMET), in Ottawa, Ontario, Canada [22]. These aggregates were used as part of an interlaboratory testing program reported in Adams et al. [21]. The AMBT and CPT expansions of the virgin aggregates used in these blocks are listed in Table 1 [21] [23]. The processed RCA samples were delivered in 3 gradations that meet the grading requirements of the concrete prism test, $3 / 4 "-1 / 2 "(3 / 4$ RCA), $1 / 2 "-3 / 8 "(1 / 2$ RCA) and $3 / 8 " 1 / 4 "(3 / 8$ RCA). A fifth RCA type was produced from a bridge in Quebec City, Quebec, Canada, that was demolished in 2010 at the end of its service life. The bridge was severely deteriorated mainly due to ASR. This RCA was processed to meet the same three gradations described above. The properties of the RCA samples 
are shown in Table 1. Also, non-reactive granitic sand was used to produce mortar bar samples with blends of RCA and non-reactive aggregate.

The concrete elements, test blocks or large concrete rubbles from the demolished bridge, were broken up using mechanical equipment on site into pieces less than $100 \mathrm{~mm}$ in diameter. These were then crushed using a crushing facility to pieces smaller than $19 \mathrm{~mm}$. Materials finer than $5.0 \mathrm{~mm}$ (sand size) was labelled crusher's fines and materials between $5.0 \mathrm{~mm}$ and $19 \mathrm{~mm}$ were labelled coarse RCA. For testing in the AMBT, coarse RCA was re-crushed to produce the gradation required by ASTM C1260 [24]. For CMBT, the coarse RCA was sieved to meet the specific sizes used in the CMBT: 5.0 to $10.0 \mathrm{~mm}(3 / 8 \mathrm{RCA})$ or $10-14 \mathrm{~mm}(1 / 2 \mathrm{RCA})$.

A virgin reactive aggregate, Spratt, from Ottawa, Ontario was used as part of the CMBT experimental program to evaluate the capacity of the test in evaluating ASR. This aggregate was chosen since the authors have a database of CPT expansions of concrete samples containing this aggregate. The CPT results were used as benchmark to evaluate the efficacy of CMBT to evaluate ASR. In addition, a non-reactive dolostone was also used in this study. For evaluating the efficacy of CMBT to test preventive measures, RCA produced from 12-year old concrete blocks containing Spratt [18] was used. This RCA was produced in a manner similar to that of the RCA from CANMET blocks. The cementing materials used in this study are listed in Table 2 along with their chemical composition. Different shipments of GU Portland cement were used as the testing was carried out at different stages over the duration of the project.

\subsection{Experimental Procedures}




\subsubsection{Accelerated mortar bar test}

The accelerated mortar bar testing (AMBT) was conducted using a modified version of the ASTM C1260 as described in Adams et al. [21]. These modifications were adopted to accommodate specific properties of RCA, mainly the high absorption. To crush the coarse RCA, the required fractions were produced from equal amounts of the three coarse fractions using large and small jaw crushers as well as a disk pulveriser. After each crushing, the material was sieved and the large particles were crushed again until all of the original material was graded. The RCA's from CANMET blocks were washed following a specified washing procedure where each size fraction was washed under a spray of clean water for a set period of time then oven dried [21]. A pre-soaking procedure was adopted to produce consistent mixes of the required workability. In this procedure, the graded RCA was mixed with the mixing water, corrected for the absorption of RCA, and left for 30 minutes prior to mixing with the rest of ingredients [21].

The RCA produced from the demolished bridge (DB) was used to evaluate the effects of the following test variables on expansion: (1) washing the processed aggregate samples, (2) minor error in the measured absorption of the sample, and (3) method of crushing.

To evaluate the effects of washing, an unwashed aggregate sample was tested and the expansion was compared to that of a washed sample. To evaluate the effect of variability or minor error in the measured absorption value, three samples were tested at: (i) the measured absorption value, (ii) absorption value minus one percent point and (iii) absorption value plus one percent point. 
To evaluate the effect of the method of crushing, a compression machine was used to process the coarse RCA to obtain the required ASTM C1260 gradation [24]. The expansion of these samples were compared to that from another sample prepared using the jaw crusher and disk pulveriser as explained above. Using the compression machine, two procedures were used as explained in the following paragraph.

The first method of compression machine crushing (Method I) was accomplished using a proctor mould, $150 \mathrm{~mm}$ in diameter by $100 \mathrm{~mm}$ in depth, and a round steel slug slightly smaller in diameter than the mould. The mould was filled with RCA and the $50 \mathrm{~mm}$-thick slug was placed on the RCA with about $5 \mathrm{~mm}$ of its thickness inserted inside the mould. The RCA samples composed of equal masses of $3 / 4 \mathrm{RCA}, 1 / 2 \mathrm{RCA}$ and $3 / 8 \mathrm{RCA}$. After $300 \mathrm{kN}$ of force was applied to the aggregate at a rate of $2 \mathrm{kN} / \mathrm{s}$, the aggregate was sieved and the material retained on the \# 8 , $\# 16$, \#30, \#50, \#100 sieves were weighed and set aside. Material retained on the \#4 (4.75 mm) sieve and sample in excess of the required masses on other sieves were collected to be further crushed in the compressive test machine. Additional RCA equal in bulk volume to that removed during sieving was added and the crushing process was repeated until a sufficient mass of each size was obtained.

The second method of crushing using compression machine (Method II) is similar to Method I except that re-crushing the oversize or excess materials took place without adding more RCA. In other words, a certain mass of RCA was used to produce the sample. After first screening, the extra materials are re-crushed until the required gradation was obtained. 


\subsubsection{Concrete micro-bar test}

The concrete microbar test involved testing samples of coarse aggregate and paste with no fine aggregate. An aggregate to cementing materials ratio of 1:1 and a water-to-cementing materials ratio of 0.33 are used. The RILEM AAR-5 method [13] requires the alkali content of the Portland cement to be boosted to $1.5 \% \mathrm{Na}_{2} \mathrm{O}_{\text {e }}$ per mass of Portland cement. Some of the mixes were cast with boosted alkalis and others without additional alkalis; samples of each category will be identified when presenting the results. The RCA used for CMBT were not processed other than being sieved and separated to the required size fractions. The aggregate specimens were prepared for mixing in large re-sealable plastic bags prior to testing. Pre-saturating the RCA was not adopted; however, the batch water was corrected for aggregate absorption. Due to the small overall volume of the batches, mixing needed to be completed using the same mixer as in the AMBT. However, the large aggregate size made it difficult to mix the aggregates into the paste. Thus, a modified mixing method conforming to the RILEM AAR-5 method [13] was created through trial and error to produce consistent batches. The standardized mixing procedure for this test was to premix the paste fraction for 2 minutes. The mixing bowl was removed from the mixer and the aggregate was added and folded into the mix with a stiff spatula. The final mixing was completed by hand to ensure complete incorporation of the paste and aggregate. The molded specimens differed from the RILEM AAR-5 standard [13] in that they were molded in customized plastic molds with a standard North American gauge length of $280 \mathrm{~mm}$ (10") rather than the $160 \mathrm{~mm}$ length described in the RILEM method. The specimens were then cured and tested in the manner prescribed in the RILEM test method to at least 28 days. Initial curing was carried out for 24 hours under standard curing condition of $100 \%$ relative humidity and room 
temperature. Following the initial curing, samples were soaked in water at $80{ }^{\circ} \mathrm{C}$ for 24 hours, after which the samples were taken out, measured immediately for its zero reading. The samples were then immersed in $1 \mathrm{~N} \mathrm{NaOH}$ solution at $80^{\circ} \mathrm{C}$ and measured periodically throughout the duration of the testing.

\section{Results}

\subsection{Accelerated Mortar Bar test}

A summary of the 14-day expansions of coarse RCA is presented in Table 3. The reported results are for coarse RCA that was crushed to produce the gradation required by ASTM C1260, which is the focus of this study. Some of the samples were repeated to evaluate the repeatability or within-laboratory variation.

Figure 1 shows mortar bar samples with $100 \%$ RCA to produce similar level of expansion, as that of the virgin aggregate, except for Springhill where the $100 \%$ RCA samples showed an expansion of $0.36 \%$ and that of the virgin aggregate showing an expansion of $0.46 \%$. For the other three aggregates, the expansions of the $100 \%$ RCA mortar bars were still lower than that of bars with the virgin aggregates, but the difference was much smaller than that in the case of Springhill. Similar finding was reported by Shehata et al. [18] where mortar bars with virgin reactive limestone produced higher expansion that bars with 100\% RCA containing the same reactive aggregate; the expansion values were $0.41 \%$ and $0.31 \%$ for virgin aggregate and RCA, respectively [18]. In the same study [18], the RCA and virgin aggregate produced similar level of 
expansion when used in concrete prisms. Potsdam aggregate showed expansion lower than $0.10 \%$ for both natural and recycled aggregates, as shown in Figure 1. This aggregate is known to produce low expansion when tested in the AMBT due to losing the reactive constituents upon crushing [25].

Table 3 also lists the results of repeated samples within the same laboratory. The difference in expansion between two samples were compared to the within-laboratory precision statement of ASTM C1260 which states "the results of two properly conducted tests within the same laboratory on specimens of a sample of aggregate should not differ by more than $8.3 \%$ of the mean expansion". As shown in the table, the differences between two test results for the samples with repeats were $<8.3 \%$ of the mean expansion. The only exception was for the DB-RCA, although the values were very close - a difference of $0.022 \%$ and $8.3 \%$ of the mean expansion is $0.020 \%$. It should be noted that for DB-RCA, the repeat (sample 2) was carried out on the same materials in the same lab but by a different operator. The $50 \%$ Bernier RCA specimens met the precision statement although the statement applies to samples with expansion $>0.10 \%$, which is not the case for this sample.

The study on the effects of variability in sample preparation on the AMBT expansion was carried out using the DB-RCA. Sample DB-RCA-1 listed in Table 3 was used as the reference sample since it was tested by the same individual who carried out the rest of the testing. The RCA used in Sample 1 was unwashed and crushed using jaw crusher and disk pulveriser as explained above under experimental procedures. 
The effect of washing is illustrated in Figure $2 \mathrm{a}$ which shows that washing the processed RCA reduces the expansion. The results are also listed in Table 4 which shows that the difference between the expansions of the washed and unwashed samples is 0.046 percent points. This value exceeds the $8.3 \%$ of the mean (0.017) specified in the precision statement of ASTM C1260 and found to be valid in this work for any tested identical two samples. This suggests that the difference is larger than what would be expected if the tested RCA samples were identical. In other words, washing the aggregate was found to have an effect on expansion beyond that of the within test variation. The reason for the high expansion of unwashed sample could be due to less alkali content in washed RCA as the washing process may leach alkalis from the sample. While the mortar bar test relies mainly on the soaking solution as the source of alkalis, internal alkalis in the system may play a significant role in expansion at earlier ages. Indeed the graph in Figure 2a shows that the rate of expansion was higher for the unwashed sample until the age of 10 days, after which the two curves were almost parallel. It should be noted that the mixtures produced using unwashed sample were workable and it is unlikely that these samples had higher porosity due to lack of workability. Had this been the case, the higher porosity could have accelerated the migration of alkalis from the soaking solution to the samples, and hence, increase the rate and ultimate expansion.

The effect of variation in moisture correction on the expansion is shown in Figure $2 \mathrm{~b}$. The objective of this experimental work is to examine if a one percent point error in the tested absorption could have an effect on the expansion. The assumption is that variability in the absorption values of RCA between different labs is likely to be within the range of \pm 1 percentage point. As shown in Figure 2b, correcting for absorption plus one percentage point 
produces slightly less expansion; however, the difference between the expansions is $<8.3 \%$ of the average, as listed in Table 4 indicating that the difference is within test variation of ASTM C1260. Correcting for absorption minus one percentage point produces more expansion. The difference between the expansions of this sample and the sample with correct moisture absorption is $0.032 \%$ which is larger than $8.3 \%$ of the average $(0.020 \%)$ as shown in Table 4 , indicating that it is outside test variation of ASTM C1260. The reason for this is unknown; however, lower water content could have produced mixtures of lower workability resulting in increased porosity which could have accelerated the migration of alkalis from the soaking solution into the bars causing higher rate and ultimate expansion.

The effect of crushing method on the expansion was much more significant than the effects of washing or moisture corrections. The results are shown in Figure 3. Crushing method I produces expansion much less than that of the sample crushed using the jaw crusher and plate pulveriser. Crushing method II produces expansion close to that of the sample crushed using the jaw crusher and plate pulveriser. This is because method I produces samples of more residual mortar than stones as the residual mortar breaks easier or faster than the stone, and the lost mass was replaced with additional RCA for subsequent crushing which contributes additional mortar to the crushed fraction. Unlike Method I, Method II involved crushing and re-crushing a finite RCA sample; this was found to produce a sample that is more representative of the coarse RCA as the method resulted in a greater contribution of fractured original stone. Figure 4 compares samples produced using Method I and Method II. As the photos show, the sample produced by method I consists of predominately residual mortar (light color) while the sample produced by method II has better representation of original stone (dark color) and residual mortar. While using a Jaw 
crusher and disk pulveriser is the preferred method and the common practice for sample preparation, the use of crushing machine was adopted here to illustrate the importance of specifying detailed sample preparation when using the AMBT to test mortars containing RCA.

\subsection{Evaluating the reactivity of Natural aggregate and RCA using the CMBT}

\subsubsection{Evaluating Spratt Natural Aggregate using the CMBT}

The CMBT was carried out initially on Spratt aggregate as this aggregate is readily available in quantity in the authors' lab. In addition, the expansion of this aggregate is well known, so the results can be used to evaluate the capacity of the CMBT to evaluate reactivity. Table 5 shows the 14, 28 and 56 day expansion results of CMBT specimens with different blends of virgin Spratt aggregate and non-reactive dolostone aggregate for sizes between $5.0 \mathrm{~mm}$ and $14 \mathrm{~mm}$. The specimens with the "@ 1.5 label” represent specimens that have had the alkali boosted to $1.5 \%$ by mass of cement while those without have only the original alkali content of the cement approximately $1 \%$. Some of the samples were repeated to confirm the obtained results; these samples are identified in the Table. The one-year expansion results of concrete prism tests carried out on some of these samples are listed in the table. In an earlier study [16], an expansion limit of $0.09 \%$ at 30 days was suggested for siliceous limestone. For other types of aggregates, an expansion limit of $0.040 \%$ was suggested $[15,16]$. It should be noted that the size of the aggregates used in the Grattan-Bellew et al. $[15,16]$ was $4.75 \mathrm{~mm}$ to $12.5 \mathrm{~mm}$. Later work carried out on 40 reactive aggregates showed that using smaller aggregate size $(2.5 \mathrm{~mm}$ to 5.0 
$\mathrm{mm}$ ) and expansion limits of $0.093 \%$ at 14 days for ASR and $0.10 \%$ at 28 days for ACR were suitable for all tested aggregates [26].

The expansion result for 100\% Spratt aggregate obtained here was lower than that obtained by Grattan-Bellew et al. [15] for the same aggregate with size of $4.75 \mathrm{~mm}$ to $12.5 \mathrm{~mm}(0.333 \%$ after 30 days [15]). To confirm the results obtained in the current study, the same aggregate was tested in the authors' lab by a different operator and similar results were obtained. For the samples tested by the second operator, two aggregate sizes were used: $4.75 \mathrm{~mm}$ to $9.5 \mathrm{~mm}$ and $9.5 \mathrm{~mm}$ to $13.2 \mathrm{~mm}$. These results along with the results of the sample tested by the first operator $(4.75 \mathrm{~mm}$ to $13.2 \mathrm{~mm}$ ) are presented in Figure 5. In addition, microbars test carried out by Shehata et al., 2010 [18], on Spratt aggregate of $4.75 \mathrm{~mm}$ to $9.5 \mathrm{~mm}$ showed an expansion of $0.19 \%$ (versus $0.203 \%$ in the current study), which showed consistent results obtained by three operators carrying the test in the same laboratory and at different timing. The reason for the different results obtained for Spratt aggregate tested here $(0.149 \%$ for $4.75 \mathrm{~mm}$ to $13.2 \mathrm{~mm}$ aggregate) and that tested by Grattan-Bellew et al. [15] $(0.333 \%)$ is not known. The Spratt in the two studies were collected from different locations within the quarry, as a new stockpile of Spratt was established in 2006 [27]. However, Spratt aggregate collected from different locations within the quarry was found to have consistent expansion results in both concrete prisms test and accelerated mortar bar test [27]. Perhaps more testing coupled with an inter-laboratory study on CMBT will be of benefit. The results in Figure 5 show that smaller size ( $4.75 \mathrm{~mm}$ to $9.5 \mathrm{~mm})$ produces higher expansion compared to larger size $(9.5 \mathrm{~mm}$ to $13.2 \mathrm{~mm})$. However, size 4.75 $\mathrm{mm}$ to $13.5 \mathrm{~mm}$ showed similar expansion to $9.5 \mathrm{~mm}$ to $13.2 \mathrm{~mm}$. This is unexpected since smaller size was found to produce higher expansion as will also be shown later in this paper. 
However, the gradation of the $4.75 \mathrm{~mm}$ to $13.5 \mathrm{~mm}$ was not investigated. In other words, there is a possibility that the majority of the particles within this range lies between $9.5 \mathrm{~mm}$ to $13.2 \mathrm{~mm}$ and hence, a similar expansion was obtained.

The results in Table 5 show that boosting the alkali content to $1.5 \%$ does not have a significant impact on the expansion results especially at later ages. Using an expansion limit of $0.09 \%$ at 28 days, $100 \%$ and $70 \%$ Spratt would fail the test, which is in agreement with the results of the CPT. However, 50\% Spratt would marginally meet the $0.09 \%$ expansion limit for CMBT [16] despite failing the CPT. This suggests that, at least for the Spratt aggregate tested here, the 0.09\% expansion limit at 28 days underestimates the CPT expansion. The level of expansions obtained in CMBT and CPT can be illustrated by representing the expansion as $\%$ of the expansion limit for both tests. These are shown in the last two columns of Table 5. It is clear that the expansion of the CMBT expressed as \% of the $0.09 \%$ limit at 28 days [16] is much less than that of the CPT. Indeed for 50\% Spratt, the CMBT showed $100 \%$ of the expansion limit while the CPT showed $350 \%$. While it is hard to establish or propose a limit based on testing only one aggregate, the results presented here suggest that a CMBT expansion limit of $0.04 \%$ at 28 days or $0.10 \%$ at 56 days would provide a greater agreement with CPT results. In terms of the effect of particle size on the expansion, the results presented in Figure 5 demonstrate that testing smaller size aggregate produces higher expansion. Hence, testing an aggregate size from $5 \mathrm{~mm}$ to $10 \mathrm{~mm}$ or $4.75 \mathrm{~mm}$ to $9.5 \mathrm{~mm}$ as opposed to $5 \mathrm{~mm}$ to $14 \mathrm{~mm}$ or $10 \mathrm{~mm}$ to $14 \mathrm{~mm}$ is recommended. This is what is adopted in RILEM test method [13].

\subsubsection{Evaluating RCA using $C M B T$}


For testing RCA in the CMBT, the water content of the mix was corrected for the absorption of the RCA. The results are shown in Figure 6 for different RCA. The results obtained for the virgin aggregate used in these RCA - available from the study of Grattan-Bellew et al. [15] - are also shown on the graphs. As was the case with testing the natural Spratt aggregate, and RCA containing Spratt in an earlier study [18], a smaller size of RCA, $5 \mathrm{~mm}$ to $10 \mathrm{~mm}$, produced higher expansion than the larger size (10 $\mathrm{mm}$ to $14 \mathrm{~mm})$. In addition, the smaller size of RCA was easier to place and compact into the moulds. Unlike the AMBT, the CMBT indicates that Potsdam RCA is likely to cause expansion since its expansion value exceeded the $0.04 \%$ expansion limit proposed by Grattan-Bellew [16] for non-limestone aggregate, which is also in agreement with its high reactivity in the CPT. This is an important advantage of CMBT over the AMBT as the latter is not capable of evaluating reactivity of some types of sandstones such as Potsdam, Lu et al., [11]. Indeed, in the accelerated mortar bar study, Potsdam RCA produced an expansion $<0.10$ at 14 days, which, misleadingly, would suggest this RCA to be non-reactive.

It is interesting to see that for Springhill and Potsdam, the expansion of samples with RCA at 28 days were similar to those for the virgin aggregates at 30 days as tested by Grattan-Bellew et al., [15]. This suggests that the reactivity of some RCA can reach that of the original aggregate used in the old concrete. This has been reported for RCA containing Spratt aggregate where the reactivity was evaluated using $\mathrm{CPT}$, CMBT and AMBT [18].

Table 6 shows the expansion expressed as \% of the expansion limit for CMBT and CPT; in this Table, the CPT expansions were for the virgin aggregate since CPT results for RCA were not 
available. Hence, the \% expansion of CPT was presented assuming that the level of the expansion of RCA would be similar to that of the virgin aggregate. This assumption could be justified, to some extent, by comparing the AMBT expansions of the RCA and the virgin aggregates reported in Table 3. In terms of expansion limit, a limit of $0.09 \%$ at 28 days [16] would be applicable to Bernier aggregate only as this is the only limestone aggregates in Table 6 . Using this limit would classify this aggregate as marginally meeting the expansion limit (the expansion is $100 \%$ of the $0.09 \%$ ). This might be correct, as the expansion of Bernier RCA in the AMBT is not very high $(0.132 \%)$. For the other aggregates, an expansion limit of $0.04 \%$ at 28 days as suggested by Grattan-Bellew et al, 2004 [16] for non-limestone aggregate provides expansion/limit ratios similar to those produced through CPT for the virgin aggregate. In general and for the four RCA, it can be stated that using expansion limits of $0.040 \%$ at 2 days or 0.10 at 56 days would classify all RCA as reactive and the level of expansion would be more comparable to the expansion of: (i) the CPT for virgin aggregate, as shown in Table 6, and (ii) AMBT for the same RCA tested here as per Table 3.

In terms of capacity of CMBT to evaluate the efficacy of preventive measures in mitigating ASR, the expansion results of CMBT and CPT containing the same blends of RCA and cementing materials are listed in Table 7. The RCA reported here contained Spratt reactive aggregates (siliceous limestone). The Table also includes the results for control RCA samples without SCM. These control samples contained Spratt-RCA used at 100\% and 70\% replacement of the total coarse aggregates. As the table shows, using an expansion limit of $0.09 \%$ at 28 days [16], would classify the three samples: (a) 70\% RCA, (b) 100\% RCA with 5\% SF - 45\% Slag, and (c) 100\% RCA with 5\% SF-25\% slag as passing the CMBT, whereas these blends failed the 
CPT. Using an expansion limit of $0.10 \%$ at 56 days would enhance the agreement between CPT and CMBT except for the sample with 5\% SF and 45\% slag where the sample would pass the CMBT and fail the CPT. Using an expansion limit of $0.04 \%$ at 28 days provides even better or safer correlations as no sample would pass the CMBT and fail the CPT, as the listed in the Table. In any case, the results in Table 7 are limited and should be interpreted with caution as will be discussed in the coming paragraphs.

Figures 7 and 8 show the relationship between CPT and CMBT results for all tested samples. The only sample that did not have a CPT result was the blend containing 5\% SF $+25 \%$ slag and Spratt-RCA. Since the CPT result for 5\% SF $+45 \%$ Slag was $0.05 \%$, it is certain that the $5 \% \mathrm{SF}$ $+25 \%$ slag would produce higher expansion. In the two graphs, this sample was assigned an estimated expansion value of $0.07 \%$ which is, in the opinion of the authors, a valid assumption based on the database of CPT expansion values available in the literature and to the knowledge of the authors. The expansion of the CPT for samples without SCM was reported at one year and for samples with SCM at two years. The graphs also include the expansion limit for the CPT which is $0.040 \%$ at one or two years for samples without and with SCM, respectively.

In Figure 7, the solid vertical line represents CMBT expansion limit of $0.09 \%$ at 28 days [16]. Using this limit, six of the tested samples would meet the CMBT limit but fail the CPT. In addition, two of these samples met the $0.09 \%$ limit with high safety margin; in other words, the CMBT expansions were between $0.04 \%$ and $0.06 \%$ which is relatively far from the $0.09 \%$ limit. The other four samples marginally met the CMBT limit (0.09\%) but severely failed the CPT. On the contrary, if the $0.040 \%$ expansion limit proposed here is used, which is represented by the 
dotted vertical line on the graph, all samples with reactive virgin aggregate or RCA would fail the test. In general, there is a better agreement between the two tests when the $0.040 \%$ expansion limit is used.

Extending the testing period to 56 days and use an expansion limit of $0.10 \%$ provided the results presented in Figure 8. The distribution of the test points in indicative of a very good agreement between the CPT and CMBT, where the discrepancy between the two test results occurred for only one sample $-100 \%$ Spratt-RCA with blend of $5 \% \mathrm{SF}+45 \%$ Slag. This is an issue, in the authors' opinion, as it provides end-users with an indication that a particular cementing blend is safe for use with a particular aggregate, when it is not.

When interpreting the results in Figures 7 and 8, the inter-laboratory and within test variation of the test methods should be considered. This is of particular important in the case of samples containing SCM tested in this study. Most of these samples marginally met the $0.040 \%$ expansion limit of CPT. Knowing the variability of CPT, the same samples can fail the test when tested by another operator or in another testing facility. This might not be an issue if a CMBT expansion limit of $0.04 \%$ at 28 days, Figure 7 , is used as these samples would fail both CMBT and CPT. However, this would be an issue if the $0.10 \%$ CMBT expansion limit at 56 days is used, Figure 8, as these samples would pass the CMBT and fail CPT. Hence, perhaps a $0.04 \%$ expansion limit at 28 days is safer, considering the aforementioned analysis. In any case, more data points (more tests) are needed for blends containing SCM before reaching a conclusion on an expansion limit. For samples without SCM, however, Figures 7 and 8 show that it is safe to use the CMBT with an expansion limit of $0.04 \%$ at 28 days or $0.10 \%$ at 56 days to predict the 
pass/fail results of CPT at one year. This is valid for the samples tested here which are the different types of RCA collected from CANMET blocks, a siliceous limestone reactive aggregate (Spratt) used at 100\%, 70\% and 30\% replacement of coarse aggregates, RCA containing Spratt, and a non-reactive dolostone.

\section{Discussion}

In an earlier study [18], it has been shown that the accelerated mortar bar test, with some modification to account for the high absorption of the RCA, can be used to evaluate reactivity of RCA and efficacy of preventive measures. The RCA used in this study was produced from a test block containing Spratt aggregate. A summary of the earlier findings [18] with two added test points are presented in Figure 9 which shows the relationship between the 14-day expansion of the AMBT and the 1- or 2-year expansion of CPT. In general, a good relation between the two tests were found. A more detailed procedure for running the AMBT on RCA was presented along with an inter-laboratory study in a paper by Adams et al. [21].

In this paper, the effects of different test parameters on the results of the AMBT were investigated using a limited number of test samples. While the study provides important information, the authors recommend testing larger number of samples and more types of RCA to confirm the results presented here. The most important parameter was found to be crushing the coarse RCA to produce the gradation required by ASTM C1260. Since RCA is composed of stone and residual mortar, it is important that the sample used in ASTM C1260 contained both material and in proportion as close as possible to the coarse RCA to be tested. Any method of crushing or processing that changes the relative proportion of residual mortar-to-stone would 
produce unreliable results. That is, more residual mortar will underestimate the expansion and more stone might overestimate it. Hence, it is highly recommended to specify an absolute sample mass and crush the entirety of the sample mass, then quarter it. Any potential specification should emphasize that a jaw crusher and disk pulveriser should be the preferred processing method and that the entirety of the sample should be crushed and processed, with several passes to ensure progressive reduction in size. A procedure similar to that specified in CSA A23.2-25A [28] is appropriate. This method requires crushing an entire $6 \mathrm{~kg}$ coarse aggregate sample and collects a representative graded sample from the crushed material.

One of the main advantages of CMBT over the AMBT is the fact that coarse aggregate does not have to be crushed to the sand-size fraction. This is of great importance for sandstones where crushing the coarse aggregate to the required fraction, whether natural or RCA, may fail to generate the expansion of the coarse fraction material, as stated earlier. However, more work is needed in the generation of a CMBT standard method to: (a) confirm its applicability to a wide range of aggregates and RCA; and (b) evaluate the suitability of the test to evaluate a wide range of SCM, and (c) establish an expansion limit with acceptable agreement with CPT results. The concrete microbar study presented here is only a step in this direction. More work covering different aggregates and SCM are needed. However, for the materials tested here, CMBT was effective in predicting the pass/fail result of CPT at one year for samples without SCM. This is the case when an expansion limit of $0.040 \%$ at 28 days or $0.10 \%$ at 56 days was used. For samples with SCM, more testing is needed although the same expansion limits showed some promises. 
Looking at the expansion limits proposed here for CMBT, one can argue that based on the results in Figures 7 and 8, the use of $0.040 \%$ limit at 28 days is a better option, in addition to its shorter duration. However, it is important to discuss and analyze the possibility of extending the test period to 56 days. Leaving the samples for 56 days in the highly alkaline soaking solution could aggravate the reaction; and hence, overestimate the expansion. Additionally and in case of SCM, the abundant supply of alkalis from the host solution might well exceed the capacity of SCM to bind alkalis and hence underestimate the capacity of SCM to alleviate the expansion. The results presented here show that the above factors did not have a measurable effect on the test results. The expansions of samples with reactive aggregate at 56 days expressed as $\%$ of the proposed limit are lower or equivalent to the expansion of CPT expressed as \% of the 2-year limit for the same aggregate. In addition, the expansions of many of the samples with SCM were still below the proposed limit.

The authors believe that extending the duration of the CMBT to 56 days does not overestimate the expansion or underestimate the efficacy of SCM due to the following factors: (a) the larger cross section of the microbars, compared to mortar bars, require more time for the alkalis to penetrate the whole cross section of the sample, (b) the coarser size of the aggregate, or the smaller reactive surface area of the particles, require more time for the reaction to proceed, and (c) for the same level SCM expressed as \% of total cementing materials, the ratio of SCM-toreactive aggregate in the CMBT samples is much higher than that in the case of the AMBT. Hence, it will take longer time for the binding capacity of the SCM to be exhausted in the case of CMBT samples compared to the AMBT. 
This paper showed that the CMBT is a promising tool to evaluate alkali-silica reactivity of RCA. Perhaps the advantage of this method as accelerated test method lies in its ability to test coarse aggregate without further crushing to the sand-size fraction needed for AMBT. This ensures that both components of RCA - primary stone and residual mortar - are represented at the same proportion and in the same condition as they are when used in concrete. Crushing the RCA to produce sand-size fraction for AMBT may also cause a loss of original ASR gel in RCA that would otherwise absorb moisture and cause expansion when tested.

In analysing the expansion results in this paper, the expansion limits for concrete with virgin aggregate were used and considered applicable to concrete with RCA. However, concrete with RCA has different properties than concrete with virgin aggregate. For instance, it was found that concrete with RCA has higher tensile creep and this was beneficial in reducing shrinkage cracking [29]. Creep under compression is also higher for concrete with RCA [30]. The effect of higher creep on the deformation that concrete can sustain due to ASR should be investigated, and the impact of this on the expansion limits requires further investigation.

\section{Conclusions:}

For the materials tested in this paper, the following conclusions are drawn:

1. Testing RCA using AMBT procedures followed in this paper was found to produce results that meet ASTM C1260 single-laboratory variation requirements.

2. Processing the aggregate, particularly RCA, with a jaw crusher followed by a disk pulveriser was found to produce a fine aggregate gradation that is representative of the coarse material aggregate-to-residual paste fraction. It is recommended to crush a pre- 
determined mass of coarse RCA (6 Kg) with several passes to ensure progressive reduction in size, followed by collecting a representative sample from the whole crushed materials.

3. Careful assessment of the RCA absorption will allow for more consistent expansion results. Variation in the absorption results will change the expansion but the effect on expansion is not as large as that if the coarse RCA was not properly crushed.

4. Washing RCA was found to slightly reduce the expansion of RCA when tested using AMBT

5. For the CMBT, the effect boosting the alkali content to $1.5 \% \mathrm{Na}_{2} \mathrm{O}_{\mathrm{e}}$ by the addition of $\mathrm{NaOH}$ produced negligible changes in the expansion of specimens at 28 or 56 days.

6. For the CMBT, using a smaller aggregate or RCA $(5-10 \mathrm{~mm})$ was found to produce higher expansion and a more workable mix than the larger size (10-14 mm).

7. For the materials tested here, CMBT was found effective in evaluating the reactivity of RCA and virgin limestone siliceous aggregate when an expansion limit of $0.04 \%$ at 28 days or $0.10 \%$ at 56 days is used.

8. For the siliceous limestone virgin aggregate and the RCA used here, good correlation was found between the 2-year expansions of CPT containing SCM and the 28-day or 56-day expansion of the CMBT containing the same cementing blends. However, more testing is needed using more RCA and SCM to identify the most appropriate CMBT expansion limit.

9. Maintaining the CMB samples in the alkaline solution for 56 days did not seem to underestimate the ability of the tested SCM to mitigate the expansion. 


\section{Acknowledgement}

This research project is funded by a grant from the Ontario Ministry of Transportation (MTO) under the Highway Infrastructure Innovation Funding Program, and a Discovery Grant from the Natural Sciences and Engineering Research Council of Canada (NSERC). The financial support of both organizations is highly appreciated. Recycled Concrete Aggregate from the demolished bridge and CANMET blocks were received courtesy of Dr. Benoit Fournier of Laval University. The authors acknowledge the support of Dr. Fournier. Opinions expressed in this paper are those of the authors and may not necessarily reflect the views and policies of the Ministry of Transportation of Ontario.

\section{References}

[1] S.Šachlová, R. Přikryl, Z. Pertold, Alkali-silica reaction products: comparison between samples from concrete structures and laboratory test specimens. Mater. Charact. 61 (12) (2010)1379-1393.

[2] S. Mindess, J.F. Young, D. Darwin, Concrete second edition. (2003) Pearson Education Ltd. USA

[3] M. Thomas, B. Fournier, K. Folliard, J. Ideker, M.H. Shehata, Test methods for evaluating preventative measures for controlling expansion due to alkali-silica reaction in concrete. Cem. Concr. Res. 36 (10) (2006)1842-1856.

[4] CSA A23.2-14A, Potential Expansivity of Aggregates (Procedure for Length Change Due to Alkali-Aggregate Reaction in Concrete Prisms), CSA International, 2014, Toronto, Ontario 207-216 
[5] M. Thomas, The effect of supplementary cementing materials on alkali-silica reaction: a review. Cem. Concr. Res. 41 (12) (2011)1224-1231.

[6] J. Duchesne, M.A. Bérubé, Long-term effectiveness of supplementary cementing materials against alkali-silica reaction. Cem. Concr. Res. 31 (7) (2001) 1057-1063.

[7] J. Lindgård, M. D.A. Thomas, E. J., S. Bård Pedersen, Ö. Andiç-Çakır, H. Justnes, T. F. Rønning, Alkali-silica reaction (ASR)—performance testing: Influence of specimen pre-treatment, exposure conditions and prism size on alkali leaching and prism expansion, Cement and Concrete Research, Volume 53, November 2013, Pages $68-90$,

[8] V. Jensen, B. Fournier, Influence of different procedures on accelerated mortar bar and concrete prism tests: assessment of seven Norwegian alkali-reactive aggregates. Proceeding of the $11^{\text {th }}$ International Conference on Alkali-Aggregate Reaction in Concrete, 11-16 June 2000, Quebec, Canada

[9] P.E. Grattan-Bellew, L. Du-you, B. Fournier, L. Mitchell, Comparison of expansions in the concrete prism and concrete microbar tests on an assorted suite of aggregates from several countries. Proceedings of the $12^{\text {th }}$ International Conference on AlkaliAggregate Reaction in Concrete, Oct. 15-19 2004, Beijing, China

[10] F.A. Innis, M.D.A.Thomas, Use of the accelerated mortar bar test to evaluate the efficacy of mineral admixtures for controlling expansion due to alkali-silica reaction. Cem. Concr. Aggreg. 21 (2) (1999)123-130.

[11] M.H. Shehata, M.D.A. Thomas, The effects of fly ash composition on the expansion of concrete due to alkali-silica reaction, Cem. Concr. Res. 30(2000)1063-1072. 
[12] D. Lu,Z. Xu,Y. Lu,M. Tang,B. Fournier,Microstructure of potsdam sandstone and applicability of accelerated tests for alkali-silica reactivity. J. Chin. Ceram. Soc. 34 (4) (2006) 458-64.

[13] H. Sommer,P.J. Nixon, I. Sims, AAR-5: Rapid preliminary screening test for carbonate aggregates. Mater. and Struct. 38(2005) 787-792.

[14] Ö. Andic-Cakir, O. Copuroglu, K. Ramyar K, Evaluation of alkali-silica reaction by concrete microbar test. ACI Mater. J. 106 (2) (2009)184-191.

[15] P.E. Grattan-Bellew, L. Du-you, B. Fournier, L. Mitchell, Proposed universal accelerated test for alkali-aggregate reaction the concrete microbar test. NRCC46876(2003)

[16] P.E. Grattan-Bellew, L. Du-you, B. Fournier, L. Mitchell, Comparison of expansions in the concrete prism and concrete microbar tests on an assorted suite of aggregates from several countries. National Research Council Canada Report, Report No. NRCC-47359, 2004.

[17] X. Li, D.L. Gress, Mitigating alkali-silica reaction in concrete containing recycled concrete aggregate. Transportation Research Board of the National Academies 1979(2006) 30-35.

[18] M.H. Shehata, C. Christidis, W. Mikhaiel, C. Rogers, M. Lachemi,Reactivity of reclaimed concrete aggregate produced from concrete affected by alkali-silica reaction. Cem. Concr. Res. 40 (4) (2010) 575-582.

[19] I.V. Scott, D.L. Gress, Mitigating alkali-silica reaction in recycled concrete. ACI SP219-5(2004) 
[20] P.E. Grattan-Bellew, Laboratory evaluation of alkali-silica reaction in concrete from Saunders generating station. ACI Mater. J. 92 (2) (1995)126-133.

[21] M.P. Adams, A. Jones, S. Beauchemin, R. Johnson, B. Fournier, M. Shehata, J.E. Tanner, and J.H. Ideker, Applicability of the accelerated mortar bar test for alkalisilica reactivity of recycled concrete aggregates. Adv. Civ. Eng. Mater. (2013) DOI:10.1520/ACEM20120030

[22] B. Fournier and V. M. Malhotra, Reducing Expansion Due to Alkali-Silica Reactivity, Concrete International, 1996, v 18, no, 3, pp: 55-59

[23] B. Fournier, Personal communication to the authors, Laval University, Quebec, Canada, 2012

[24] ASTM C1260 "Standard Test Method for Potential Alkali Reactivity of Aggregates (Mortar-Bar Method)"West Conshohocken, PA: ASTM, 2007

[25] D. Lu, B. Fournier, P.E. Grattan-Bellew, Evaluation of accelerated test methods for determining alkali-silica reactivity of concrete aggregates. Cem. Concr. Compos. 28 (6) (2006)546-554.

[26] Lu D, Fournier B, Grattan-Bellew P, Xu Z, Tang M Development of a universal accelerated test for alkali-silica and alkali-carbonate reactivity of concrete aggregates. Mat. and Struct. 41(2) (2008) 235-246.

[27] B. Fournier, C. Rogers and C-A. Macdonald, Multilaboratory Study of the Concrete Prism and Accelerated Mortar Bar Expansion Tests with Spratt Aggregate, $14^{\text {th }}$ International Conference on Alkali-Aggregate Reaction, Austin, Tx. 2012. 
[28] CSA A23.2-25A, Test method for detection of alkali-silica reactive aggregate by accelerated expansion of mortar bars, CSA International, 2014, Toronto, Ontario 358365

[29] J. Henschen,, A. Teramoto, D.A. Lange, Shrinkage and creep performance of recycled aggregate concrete. $7^{\text {th }}$ RILEM international conference on cracking in pavements, pp. 1333-1340, January 2012, Springer Netherlands.

[30] G. Fathifazl, A. Ghani Razaqpur, O. Burkan Isgor, A. Abbas, B. Fournier, S. Foo, Creep and drying shrinkage characteristics of concrete produced with coarse recycled concrete aggregate, Cement and Concrete Composites, Volume 33, Issue 10, November 2011, Pages 1026-1037, ISSN 0958-9465. 
Table 1: Sources and properties of RCA

\begin{tabular}{|c|c|c|c|c|c|}
\hline \multirow[b]{2}{*}{ RCA } & \multirow[b]{2}{*}{$\begin{array}{l}\text { Virgin Aggregate } \\
\text { Type }\end{array}$} & \multirow{2}{*}{$\begin{array}{l}\text { Source of virgin } \\
\text { reactive aggregate }\end{array}$} & \multirow{2}{*}{$\begin{array}{l}\text { Absorption } \\
\text { of the } \\
\text { Coarse } \\
\text { RCA } \\
{[21][23]}\end{array}$} & \multicolumn{2}{|c|}{$\begin{array}{c}\text { Expansion of virgin } \\
\text { aggregates [21][23] }\end{array}$} \\
\hline & & & & $\begin{array}{l}\text { AMBT at } \\
14 \text { days }\end{array}$ & $\begin{array}{l}\text { CPT at } \\
1 \text { Year }\end{array}$ \\
\hline Block -Alberta & Natural Gravel & Calgary, Alberta & 6.66 & 0.36 & 0.09 \\
\hline Block-Bernier & $\begin{array}{l}\text { Argillaceous } \\
\text { Limestone }\end{array}$ & $\begin{array}{l}\text { St-Jean sur le } \\
\text { Richelieu, Quebec }\end{array}$ & 6.18 & 0.17 & 0.07 \\
\hline Block-Potsdam & Siliceous Sandstone & Montreal, Quebec & 4.22 & 0.09 & 0.13 \\
\hline $\begin{array}{l}\text { Block- } \\
\text { Springhill }\end{array}$ & $\begin{array}{l}\text { Greywacke and } \\
\text { Argillite }\end{array}$ & $\begin{array}{l}\text { Fredericton, New } \\
\text { Brunswick }\end{array}$ & 7.78 & 0.46 & 0.22 \\
\hline $\begin{array}{l}\text { Quebec } \\
\text { Demolished } \\
\text { Bridge (DB) }\end{array}$ & Siliceous limestone & Quebec City & 4.90 & & \\
\hline
\end{tabular}

Table 2: Major oxide composition of cementing materials used in this study

\begin{tabular}{|c|c|c|c|c|c|c|c|c|c|c|c|}
\hline $\begin{array}{l}\mathrm{CM} \\
\text { Sample }\end{array}$ & $\mathrm{CaO}$ & $\mathrm{SiO}_{2}$ & $\mathrm{Al}_{2} \mathrm{O}_{3}$ & $\mathrm{Fe}_{2} \mathrm{O}_{3}$ & $\mathrm{MgO}$ & $\mathrm{SO}_{3}$ & $\mathrm{~K}_{2} \mathrm{O}$ & $\mathrm{Na}_{2} \mathrm{O}$ & $\mathrm{TiO}_{2}$ & $\mathrm{P}_{2} \mathrm{O}_{5}$ & $\mathrm{Na}_{2} \mathrm{O}_{\mathrm{e}}$ \\
\hline $\mathrm{PC} \mathrm{A}^{*}$ & 60.8 & 19.6 & 4.88 & 2.91 & 2.52 & 3.3 & 0.97 & 0.27 & - & - & 0.91 \\
\hline PC B* & 63.3 & 19.9 & 5.22 & 2.73 & 2.64 & 4.7 & 1.20 & 0.24 & 0.27 & 0.14 & 1.03 \\
\hline $\mathrm{PC} \mathrm{C}^{*}$ & 62.8 & 20.6 & 5.58 & 2.28 & 2.34 & 4.6 & 1.20 & 0.28 & 0.27 & 0.13 & 1.07 \\
\hline LCFA* & 4.43 & 55.7 & 27.4 & 5.59 & 1.56 & 0.26 & 2.29 & 0.44 & 0.67 & 0.31 & 1.95 \\
\hline Slag* & 43.2 & 34.4 & 7.4 & 0.94 & 9.3 & 0.83 & 0.58 & 0.57 & 0.44 & 0 & 0.95 \\
\hline $\mathrm{SF}^{*}$ & 0.27 & 95.2 & 0.35 & 0.10 & 0.91 & 0.25 & 0.51 & 0.21 & 0.13 & 0.13 & 0.55 \\
\hline \multicolumn{12}{|l|}{ *Notes: } \\
\hline PC A: & \multirow{3}{*}{\multicolumn{11}{|c|}{$\begin{array}{l}\text { Type GU Portland Cement used in AMBT with the } 4 \text { RCA from CANMET blocks } \\
\text { Type GU Portland Cement used with virgin Spratt in CMBT } \\
\text { Type GU Portland Cement used in CMB with RCA and AMBT with RCA from } \\
\text { Demolished Bridge (DB) }\end{array}$}} \\
\hline PC B: & & & & & & & & & & & \\
\hline PC C: & & & & & & & & & & & \\
\hline LCFA: & \multicolumn{11}{|c|}{ Low Calcium Fly Ash } \\
\hline HCFA: & \multicolumn{11}{|c|}{ High Calcium Fly Ash } \\
\hline Slag: & \multicolumn{11}{|c|}{ Ground Granulated Blast Furnace Slag } \\
\hline SF: & \multicolumn{11}{|c|}{ Silica Fume } \\
\hline
\end{tabular}


Table 3: Expansions and repeatability of RCA samples tested using AMBT

\begin{tabular}{|c|c|c|c|c|c|}
\hline \multirow[b]{2}{*}{ Aggregate Type } & \multicolumn{2}{|c|}{ Expansion at 14 days $(\%)$} & \multirow[b]{2}{*}{$\begin{array}{l}\text { Mean } \\
(\%)\end{array}$} & \multirow{2}{*}{$\begin{array}{l}\text { Difference } \\
\text { Between } \\
\text { Expan. of the } \\
\text { two samples } \\
(\% \text { of the } \\
\text { mean })\end{array}$} & \multirow{2}{*}{$\begin{array}{l}8.3 \% \\
\text { of Mean } \\
\text { Expansion }\end{array}$} \\
\hline & Sample 1 & $\begin{array}{l}\text { Sample } 2 \\
\text { (Repeat) }\end{array}$ & & & \\
\hline Alberta Virgin Aggregate & 0.360 & & & & \\
\hline Alberta $100 \%$ RCA & 0.338 & & & & \\
\hline Alberta $50 \%$ RCA & 0.316 & 0.308 & 0.312 & 0.008 & 0.026 \\
\hline Alberta $25 \%$ RCA & 0.231 & 0.236 & 0.234 & 0.005 & 0.019 \\
\hline Bernier Virgin Aggregate & 0.170 & & & & \\
\hline Bernier $100 \%$ RCA & 0.132 & & & & \\
\hline Bernier $50 \%$ RCA & 0.083 & 0.081 & 0.082 & 0.003 & 0.007 \\
\hline Potsdam Virgin Aggregate & 0.090 & & & & \\
\hline Potsdam $100 \%$ RCA & 0.073 & & & & \\
\hline Potsdam 50\% RCA & 0.066 & & & & \\
\hline Potsdam 25\% RCA & 0.065 & & & & \\
\hline Springhill Virgin Aggregate & 0.460 & & & & \\
\hline Springhill $100 \%$ RCA & 0.357 & 0.376 & 0.366 & 0.020 & 0.030 \\
\hline Springhill 50\% RCA & 0.300 & & & & \\
\hline Springhill 25\% RCA & 0.220 & & & & \\
\hline $\begin{array}{l}\text { Quebec Demolished Bridge } \\
\text { (DB-RCA) }\end{array}$ & 0.230 & 0.252 & 0.241 & 0.022 & 0.020 \\
\hline
\end{tabular}


Table 4: Effects of different parameters on the expansion of mortar bars with RCA

\begin{tabular}{|c|c|c|c|c|c|}
\hline \multicolumn{6}{|c|}{ Effect of Washing } \\
\hline & \multicolumn{2}{|c|}{ Expansion at 14 days $(\%)$} & \multirow[b]{2}{*}{ Mean } & \multirow{2}{*}{$\begin{array}{l}\text { Difference } \\
\text { Between } \\
\text { Expan. of the } \\
\text { two samples } \\
\text { (\% points) }\end{array}$} & \multirow{2}{*}{$\begin{array}{l}8.3 \% \\
\text { of Mean } \\
\text { Expansion }\end{array}$} \\
\hline & Unwashed & Washed & & & \\
\hline Quebec Demolished Bridge & 0.230 & 0.184 & 0.207 & 0.046 & 0.017 \\
\hline \multicolumn{6}{|c|}{ Effect of Errors in Aggregate Absorption } \\
\hline & \multicolumn{2}{|c|}{ Expansion at 14 days $(\%)$} & & \multirow[b]{2}{*}{$\begin{array}{l}\text { Difference } \\
\text { Between } \\
\text { Expan. of the } \\
\text { two samples } \\
(\%)\end{array}$} & \multirow[b]{2}{*}{$\begin{array}{l}8.3 \% \\
\text { of Mean } \\
\text { Expansion }\end{array}$} \\
\hline & $\begin{array}{l}\text { Correcting } \\
\text { for Exact } \\
\text { absorption } \\
4.9 \% \\
\end{array}$ & $\begin{array}{l}\text { Correcting } \\
\text { for Absorp. } \\
+1 \text { pctg. } \\
\text { Point:5.9\% }\end{array}$ & Mean & & \\
\hline \multirow[t]{3}{*}{ Quebec Demolished Bridge } & 0.230 & 0.219 & 0.224 & 0.011 & 0.019 \\
\hline & \multicolumn{2}{|c|}{ Expansion at 14 days $(\%)$} & & \multirow[b]{2}{*}{$\begin{array}{l}\text { Difference } \\
\text { Between } \\
\text { Expan. of the } \\
\text { two samples } \\
(\%)\end{array}$} & \multirow[b]{2}{*}{$\begin{array}{l}8.3 \% \\
\text { of Mean } \\
\text { Expansion }\end{array}$} \\
\hline & $\begin{array}{l}\text { Correcting } \\
\text { for Exact } \\
\text { absorption } \\
4.9 \% \\
\end{array}$ & $\begin{array}{l}\text { Correcting } \\
\text { for Absorp. } \\
-1 \text { pctg. } \\
\text { Point: } 3.9 \%\end{array}$ & Mean & & \\
\hline Quebec Demolished Bridge & 0.230 & 0.262 & 0.246 & 0.032 & 0.020 \\
\hline
\end{tabular}


Table 5: Expansion of virgin Spratt aggregate and blends of Spratt/non-reactive aggregates using CPT and CMBT

\begin{tabular}{|c|c|c|c|c|c|c|}
\hline \multirow[t]{2}{*}{ Aggregate } & \multicolumn{3}{|c|}{$\begin{array}{l}\text { CMBT Expansion at } \\
\text { different ages }(\%)\end{array}$} & \multirow{2}{*}{$\begin{array}{l}C P T \\
\text { Expansion } \\
\text { at } 1 \text { year } \\
(\%)\end{array}$} & \multirow{2}{*}{$\begin{array}{l}\text { CPT } \\
\text { Expansion } \\
\text { as\% of 1- } \\
\text { year Limit } \\
(0.04 \%)\end{array}$} & \multirow{2}{*}{$\begin{array}{l}\text { CMBT } \\
\text { Expansion } \\
\text { as \% of 28- } \\
\text { day Limit } \\
\text { of } 0.09 \text { [16] }\end{array}$} \\
\hline & 14 Days & 28 Days & 56 Days & & & \\
\hline $100 \%$ Spratt & 0.083 & 0.142 & 0.250 & & & \\
\hline 100\% Spratt @ 1.5 & 0.099 & 0.149 & 0.211 & 0.202 & 510 & 170 \\
\hline $70 \%$ Spratt & 0.058 & 0.105 & 0.183 & & & \\
\hline 70\% Spratt@ 1.5 & 0.071 & 0.111 & 0.174 & 0.147 & 370 & 120 \\
\hline $50 \%$ Spratt & 0.047 & 0.083 & 0.143 & & & \\
\hline 50\% Spratt @1.5 & 0.056 & 0.090 & 0.146 & 0.139 & 350 & 100 \\
\hline $50 \%$ Spratt Repeat & 0.050 & 0.091 & 0.162 & & & \\
\hline 50\% Spratt Repeat @ 1.5 & 0.056 & 0.089 & 0.136 & 0.139 & 350 & 100 \\
\hline $30 \%$ Spratt & 0.037 & 0.065 & 0.104 & & & \\
\hline 30\% Spratt @1.5 & 0.036 & 0.058 & 0.083 & & & \\
\hline $30 \%$ Spratt Repeat & 0.037 & 0.069 & 0.116 & & & \\
\hline 30\% Spratt Repeat@1.5 & 0.037 & 0.060 & 0.092 & & & \\
\hline $10 \%$ Spratt & 0.020 & 0.030 & 0.047 & & & \\
\hline 10\% Spratt @ 1.5 & 0.020 & 0.028 & 0.043 & & & \\
\hline Non-Reactive & 0.015 & 0.022 & 0.029 & & & \\
\hline Non-Reactive@ 1.5 & 0.011 & 0.012 & 0.017 & 0.021 & 50 & 10 \\
\hline
\end{tabular}


Table 6: Expansion of different RCA using CMBT and AMBT, and the virgin aggregates using CPT

\begin{tabular}{|c|c|c|c|c|c|c|c|c|}
\hline Aggregate & $\begin{array}{l}\text { CMBT } \\
\text { Exp. at } \\
28 \text { days } \\
(\%)\end{array}$ & $\begin{array}{l}\text { CMBT } \\
\text { Exp. at } \\
56 \text { days } \\
(\%)\end{array}$ & $\begin{array}{l}A M B T \\
\text { of } R C A \\
\text { at } 14 \\
\text { days } \\
(\%)\end{array}$ & $\begin{array}{l}C P T \\
\text { Exp. of } \\
\text { virgin } \\
\text { agg. } \\
\text { at } 1 \text { year } \\
(\%)\end{array}$ & $\begin{array}{l}\text { CMBT } \\
\text { Exp. } \\
\% \text { of 28- } \\
\text { day Limit } \\
\text { of } 0.09 \text { [16] }\end{array}$ & $\begin{array}{l}\text { CMBT } \\
\text { Exp. } \\
\% \text { of 56- } \\
\text { day } \\
\text { proposed } \\
\text { Limit } \\
(0.10 \%)\end{array}$ & $\begin{array}{l}\text { CMBT } \\
\text { Exp. } \\
\% \text { of 28- } \\
\text { day } \\
\text { proposed } \\
\text { Limit** } \\
(0.04 \%)\end{array}$ & $\begin{array}{l}\text { CPT } \\
\text { Exp. } \\
\% \text { of } \\
\text { 1-year } \\
\text { Limit }\end{array}$ \\
\hline Alberta & 0.129 & 0.220 & 0.338 & 0.09 & N/A* & 220 & 323 & 230 \\
\hline Bernier & 0.086 & 0.155 & 0.132 & 0.07 & 100 & 150 & 214 & 180 \\
\hline Potsdam & 0.121 & 0.215 & 0.073 & 0.13 & N/A* & 220 & 301 & 330 \\
\hline Springhill & 0.142 & 0.237 & 0.357 & 0.22 & N/A* & 240 & 354 & 550 \\
\hline \multicolumn{9}{|c|}{$\begin{array}{l}\text { *: the virgin aggregates used in these RCAs are not siliceous limestone, so the } 0.09 \% \text { at } 28 \text { proposed by } \\
\text { Grattan-Bellew et al., } 2004 \text { [16] does not apply (assuming same limit applies to Virgin aggregate and RCA } \\
\text { containing same aggregate). }\end{array}$} \\
\hline \multicolumn{9}{|c|}{$\begin{array}{l}\text { **: An expansion limit of } 0.04 \% \text { was also recommended by Grattan-Bellew et al., } 2004 \text { [16] for non- } \\
\text { limestone virgin aggregates }\end{array}$} \\
\hline
\end{tabular}


Table 7: Expansion of CPT and CMBT for samples with Spratt-RCA and SCM

\begin{tabular}{|c|c|c|c|c|c|c|c|}
\hline Sample & $\begin{array}{l}\text { CMBT } \\
\text { Exp. at } \\
28 \text { days } \\
(\%)\end{array}$ & $\begin{array}{l}\text { CMBT } \\
\text { Exp. at } \\
56 \text { days } \\
(\%)\end{array}$ & $\begin{array}{l}C P T \\
\text { Exp. } \\
\text { at } 1 \text { or } 2 \\
\text { years* } \\
(\%)\end{array}$ & $\begin{array}{l}\text { CMBT } \\
\text { Exp. } \\
\% \text { of 28- } \\
\text { day Limit } \\
(0.09[16])\end{array}$ & $\begin{array}{l}\text { CMBT } \\
\text { Exp. } \\
\% \text { of } \\
\text { 56-day } \\
\text { proposed } \\
\text { Limit } \\
(0.10 \%) \\
\end{array}$ & $\begin{array}{l}\text { CMBT } \\
\text { Exp. } \\
\% \text { of } \\
\text { 28-day } \\
\text { proposed } \\
\text { Limit } \\
(0.04 \%)\end{array}$ & $\begin{array}{l}\text { CPT } \\
\text { Exp. } \\
\% \text { of 1- } \\
\text { or 2-year } \\
\text { Limit* }\end{array}$ \\
\hline RCA $100 \%$ & 0.180 & 0.325 & 0.210 & 200 & 325 & 450 & 525 \\
\hline $20 \%$ LCFA + $30 \%$ Slag & 0.041 & 0.070 & 0.035 & 45 & 70 & 103 & 88 \\
\hline $5 \% \mathrm{SF}+20 \% \mathrm{LCFA}$ & 0.060 & 0.115 & 0.040 & 67 & 115 & 150 & 100 \\
\hline $5 \% \mathrm{SF}+30 \% \mathrm{LCFA}$ & 0.045 & 0.082 & 0.037 & 50 & 82 & 113 & 93 \\
\hline $5 \% \mathrm{SF}+25 \%$ Slag & 0.082 & 0.154 & N/A** & 91 & 154 & 205 & N/A \\
\hline $5 \% \mathrm{SF}+45 \%$ Slag & 0.044 & 0.083 & 0.050 & 49 & 83 & 110 & 125 \\
\hline $70 \% \mathrm{RCA}$ & 0.086 & 0.150 & 0.112 & 95 & 150 & 215 & 280 \\
\hline $70 \%$ RCA + $25 \%$ LCFA & 0.052 & 0.093 & 0.034 & 58 & 93 & 130 & 85 \\
\hline $70 \%$ RCA $+50 \%$ slag & 0.055 & 0.100 & 0.034 & 61 & 100 & 138 & 85 \\
\hline
\end{tabular}

*: 1 year for samples with no SCM and 2 years for samples with SCM

**: CPT result is not available for this sample but it is anticipated to be in excess of $0.04 \%$ (failure) since the blend with 5\% SF - \% /45 Slag showed 0.05\% (failed). In Figures 7 and 8, an estimated value of $0.07 \%$ was assigned to this mix based on results of 5\% SF-45\% Slag sample 

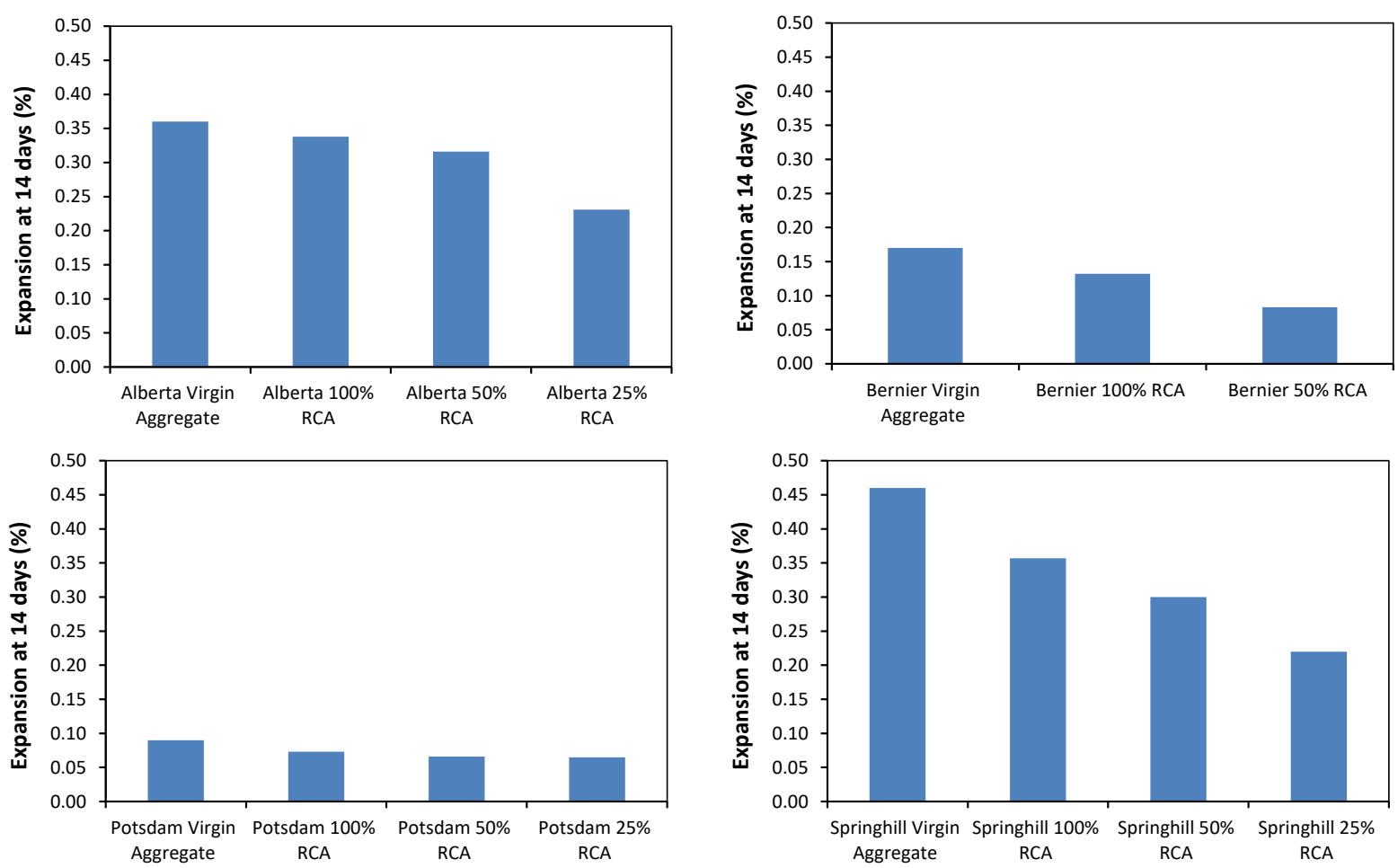

Figure 1: Expansion of mortar bar samples containing different virgin aggregates and RCA produced from old concrete containing the same aggregates.

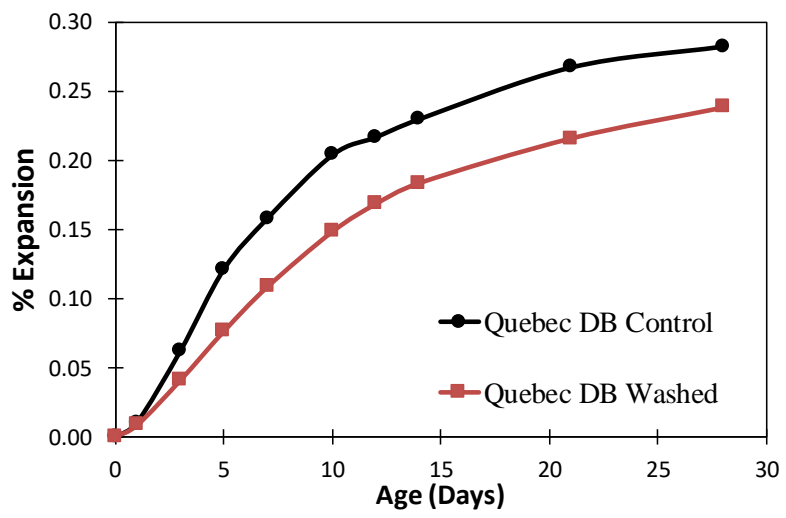

(a)

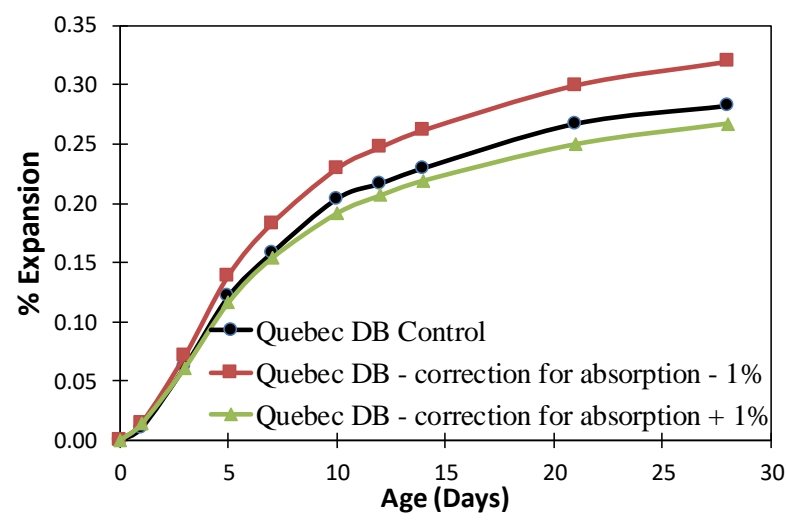

(b)

Figure 2: Effects of: (a) washing and (b) variability in moisture correction on the expansion of mortar bars. 


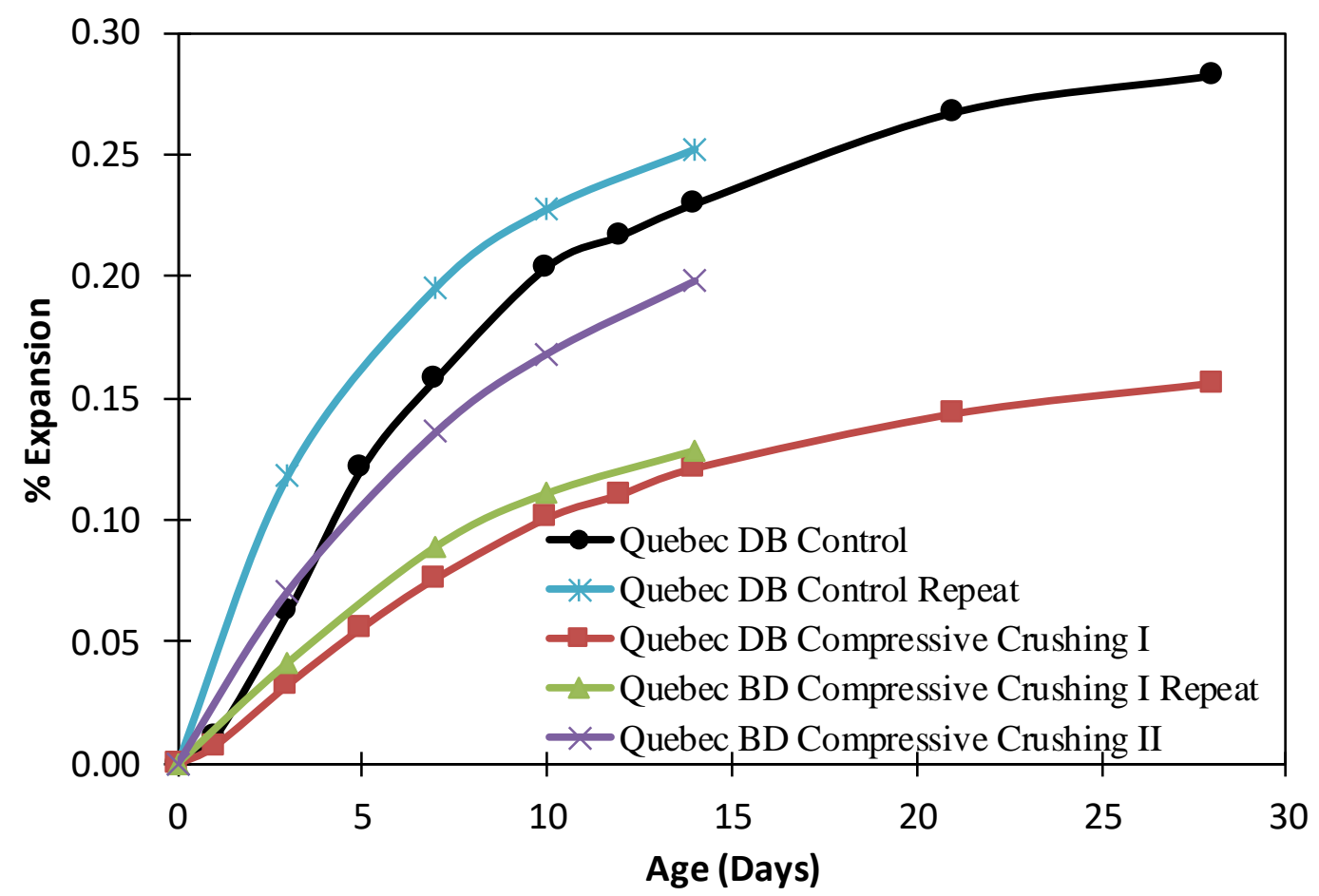

Figure 3: Effect of method of crushing on expansion of mortar bars containing RCA

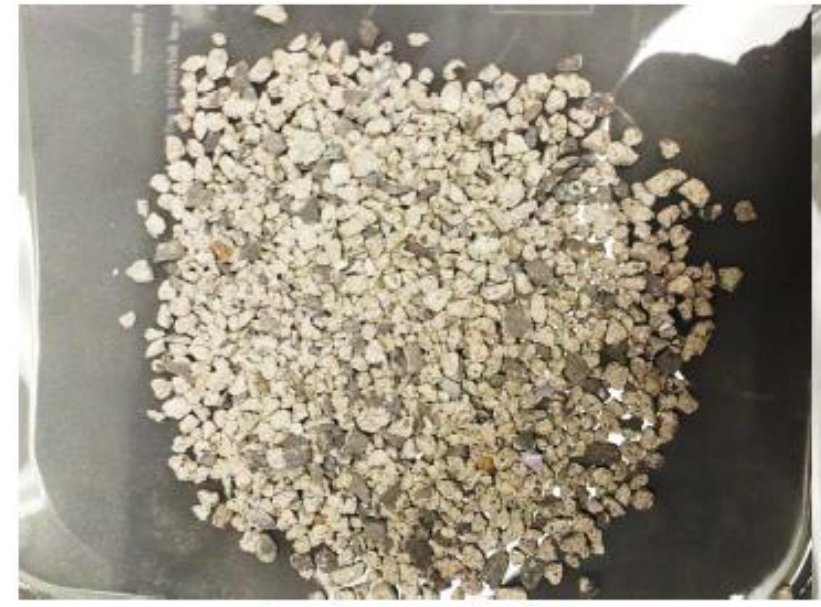

Crushing Method I

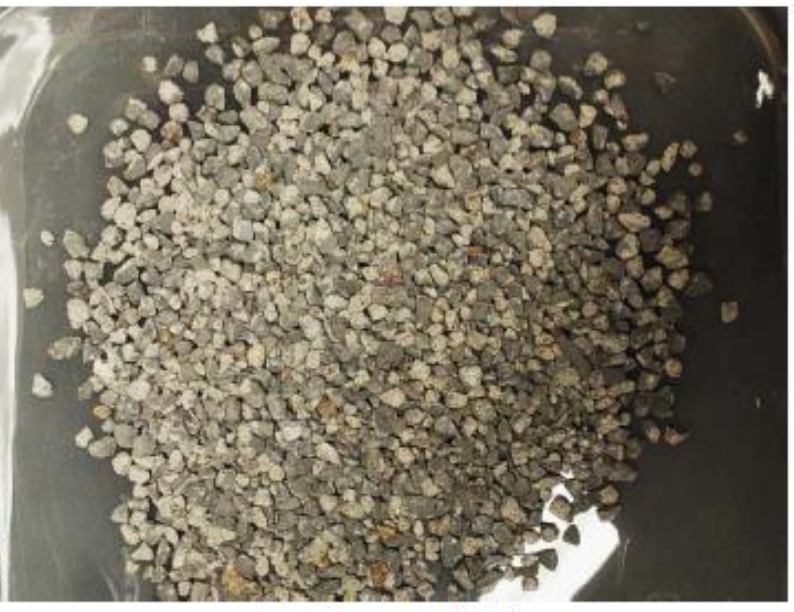

Crushing Method II

Figure 4: Aggregate sample prepared using crushing methods I and II. Note the relative volume of original aggregate (dark grey) to residual mortar (light grey) in both cases. 


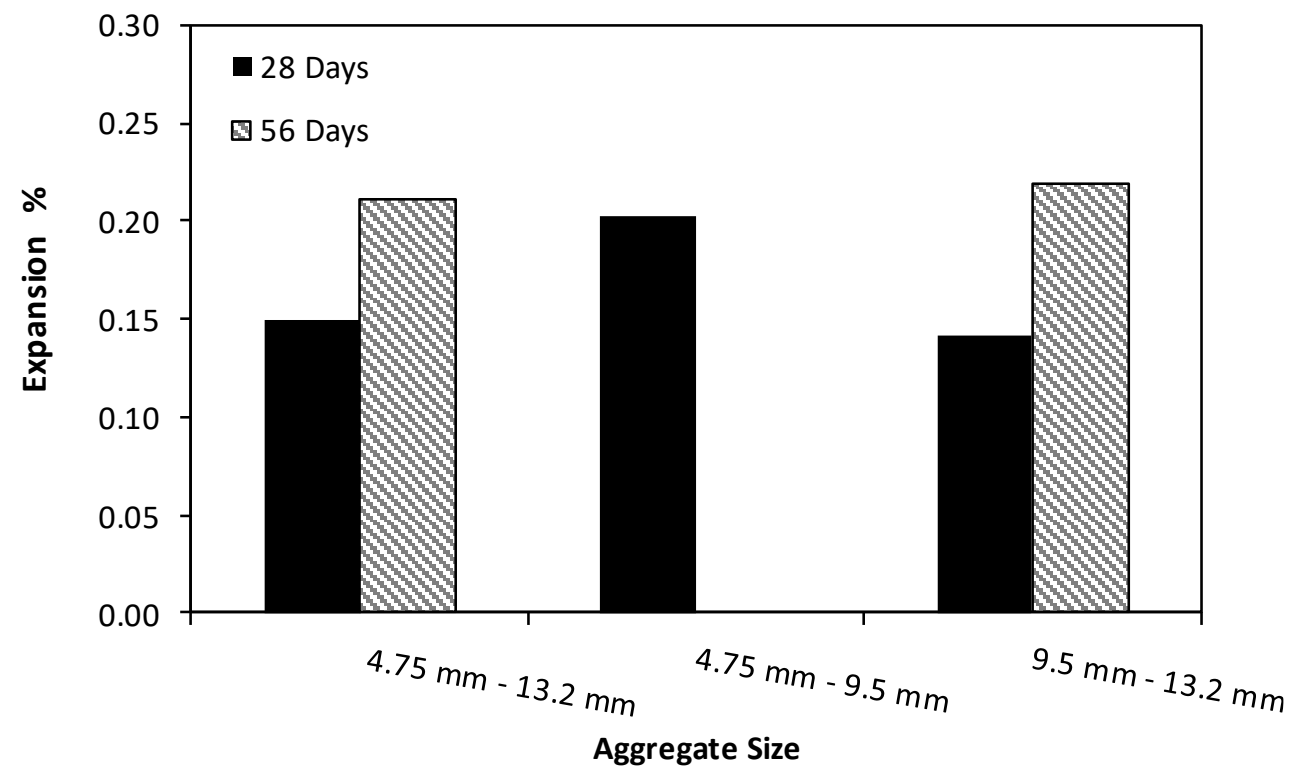

Figure 5: Expansion of CMB samples containing different sizes of Spratt aggregate 

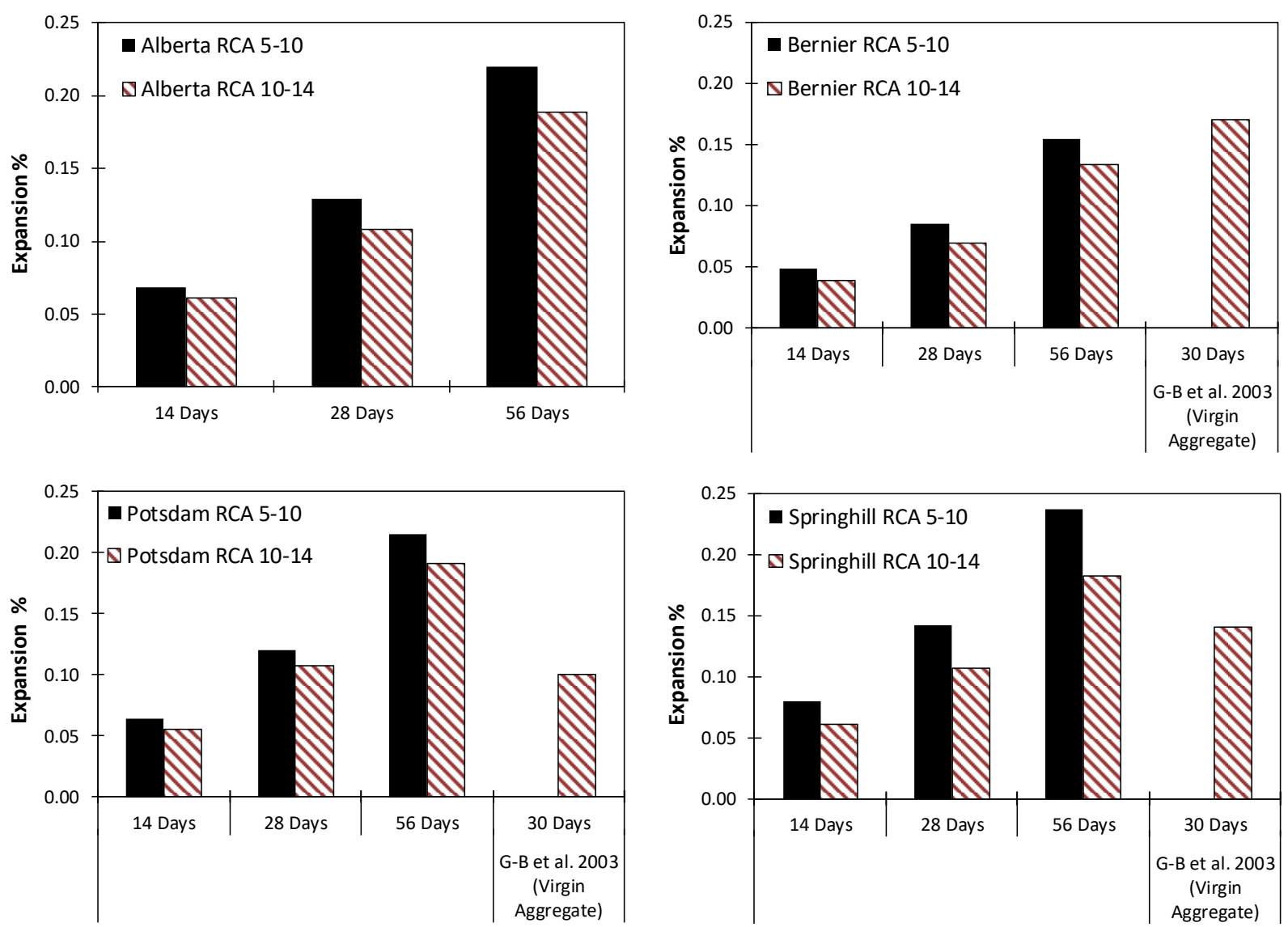

Figure 6:Expansion of CMB containing RCA processed from concrete containing Alberta, Bernier, Potsdam and Springhill RCA along with the expansion of CMB containing virgin Bernier, Potsdam and Springhill reproduced from Grattan-Bellew et al [15]. 


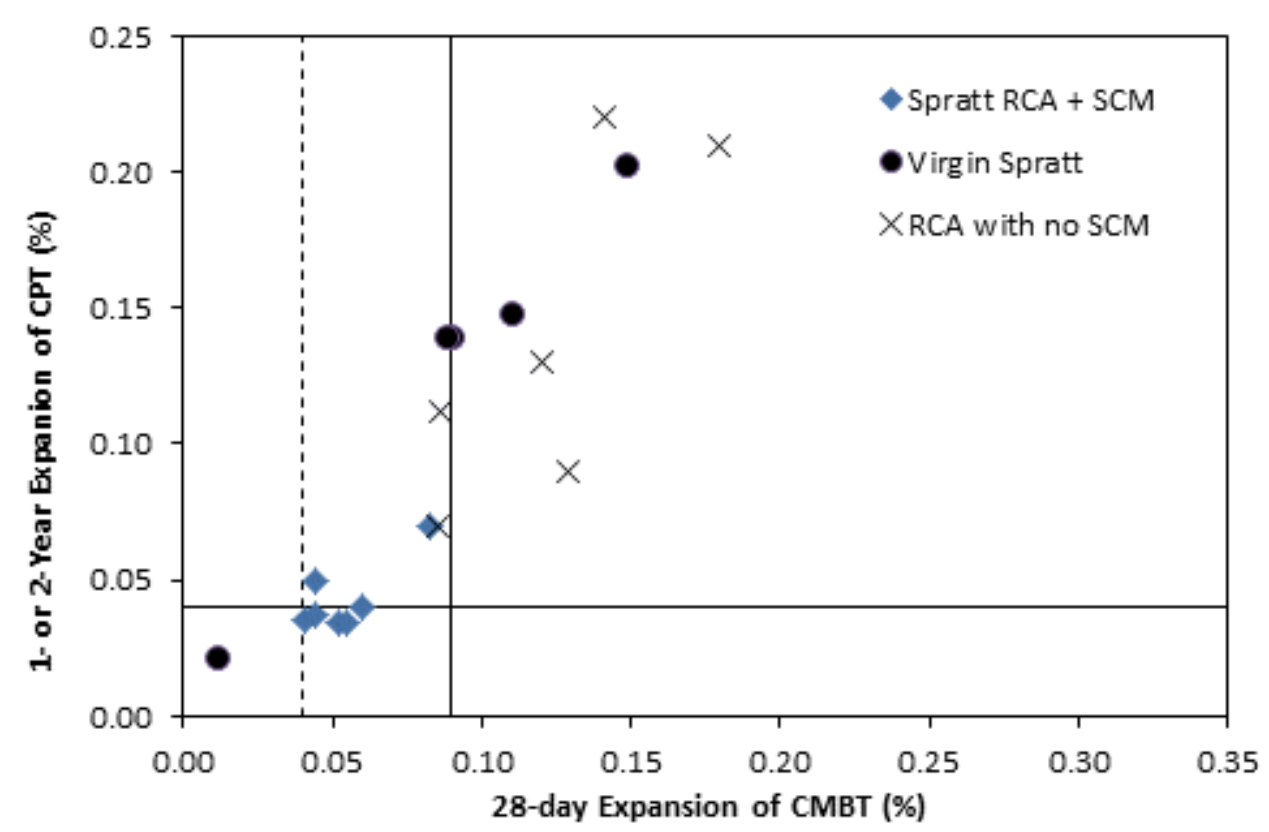

Figure7: Expansion of CPT at one year for samples without SCM and two years for samples with SCM versus 28-day expansion of the CMBT.

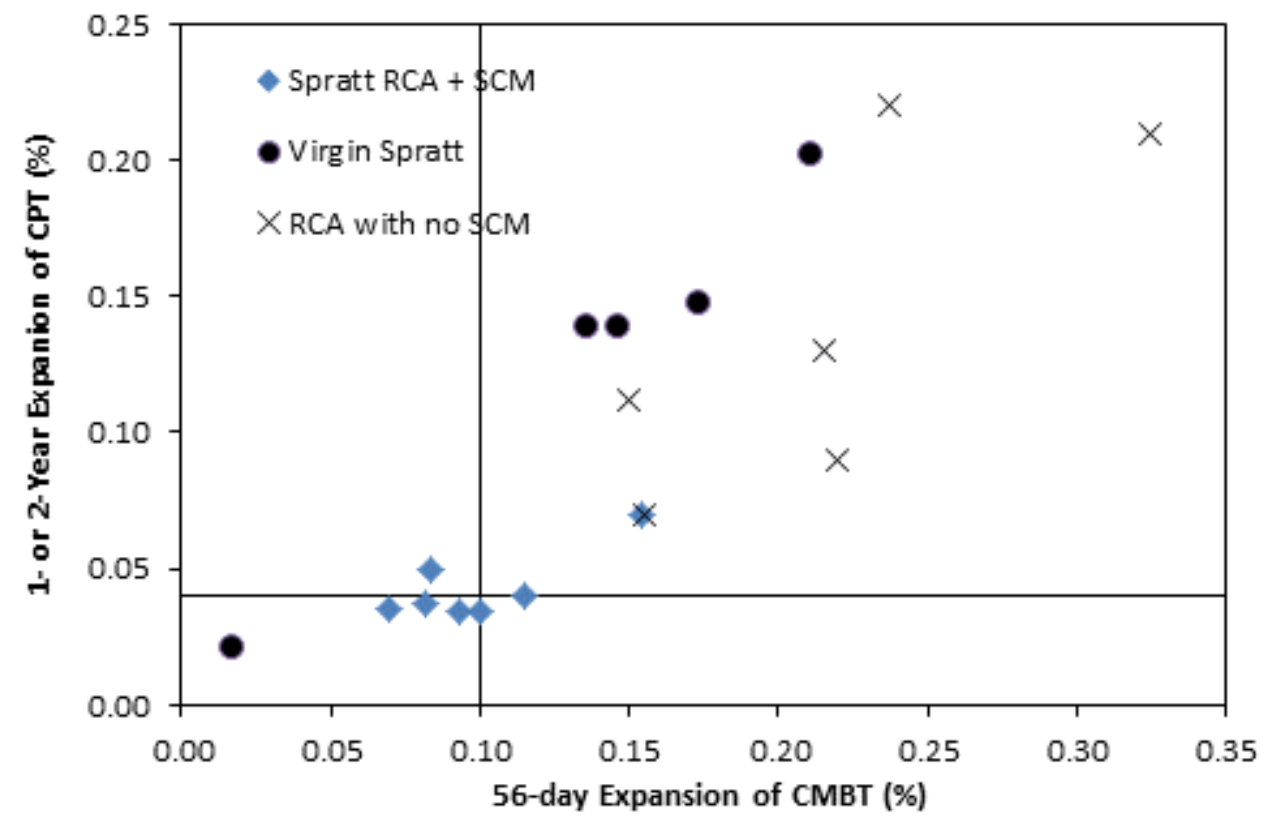

Figure 8: Expansion of CPT at one year for samples without SCM and two years for samples with SCM versus 56-day expansion of the CMBT. 


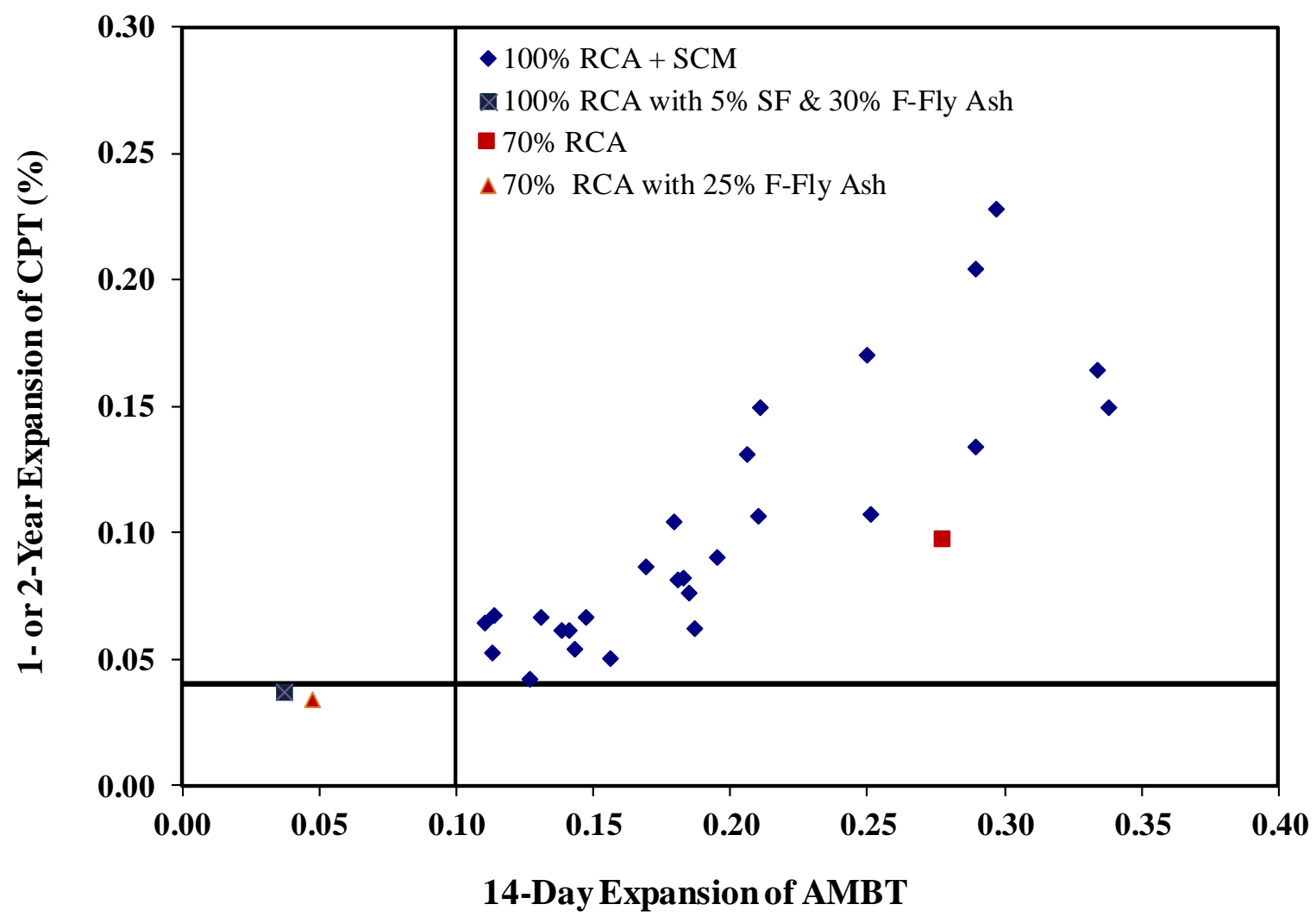

Figure 9: Expansions of CPT at one or two years versus 14-day expansions of AMBT for concrete or mortar containing RCA produced from concrete containing Spratt reactive aggregate (reproduced from [18]) 